\title{
Pretreatment Serum Cea as a Predictive Biomarker for the Response to Neoadjuvant Chemoradiotherapy: A Meta-Analysis in Rectal Cancer
}

\author{
Huichuan $\mathrm{Yu}^{1}$, Wenhao Chen ${ }^{1}$, Yonghua Cai ${ }^{1}$, Yanxin Luo ${ }^{1,2}$, Liang Kang ${ }^{1}$, Meijin Huang ${ }^{1}$, Hui Peng ${ }^{1}$ and Jianping Wang ${ }^{1,2}{ }^{*}$
}

${ }^{1}$ Department of Colon and Rectum Surgery, the Sixth Affiliated Hospital (Guangdong Gastrointestinal and Anal Hospital), Sun Yat-sen University, Guangzhou, Guangdong, 510655, China

${ }^{2}$ Guangdong Institute of Gastroenterology, the Sixth Affiliated Hospital (Guangdong Gastrointestinal and Anal Hospital), Sun Yat-sen University, Guangzhou, Guangdong, 510655, China

"Corresponding author: Jianping Wang, Department of Colon and Rectum Surgery, Guangdong Institute of Gastroenterology, the Sixth Affiliated Hospital (Guangdong Gastrointestinal and Anal Hospital), Sun Yat-sen University, 26 Yuancun Erheng Road, Guangzhou, Guangdong 510655, People's Republic of China, Tel: +86 20 38254955 ; Fax: +86 20 38254094; E-mail: jpwanggz@gmail.com

Recieved date: Aug 02, 2015; Accepted date: Sep 23, 2015; Published date: Sep 29, 2015

Copyright: $\odot 2015 \mathrm{Yu} \mathrm{H}$, et al. This is an open-access article distributed under the terms of the Creative Commons Attribution License, which permits unrestricted use, distribution, and reproduction in any medium, provided the original author and source are credited.

\begin{abstract}
Background: It is important to predict patients with rectal cancer responding well to neoadjuvant chemoradiotherapy (nCRT). Numerous studies have yielded inconsistent results regarding the relationship between pretreatment CEA level and the response to nCRT in patients with rectal cancer. We conducted a systematic review and meta-analysis of these studies to define the relationship between them.

Methods: A literature search of all major databases was performed. A total of 14 previously published eligible studies including 3,705 cases were identified and included in this meta-analysis. Results: Normal CEA $(<5 \mathrm{ng} / \mathrm{ml})$ predicted improved pathological complete response (pCR) (FE: RR 3.33; 95\% Cl 2.57-4.31; P<0.00001) and good response (FE: RR 1.86; 95\% Cl 1.08-3.21; P < 0.00001) to nCRT. Moreover, Normal CEA was significantly associated with decreased poor response (RE: RR 0.78; 95\% Cl 0.73-0.83; P<0.00001) to nCRT.

Conclusions: The current meta-analysis suggests that pretreatment normal CEA level is a useful predictive factor for response to neoadjuvant treatment in patients with rectal cancer. The validated predictive value of pretreatment CEA on PCR should be considered in the design of further clinical studies to determine the safety and efficacy of wait-and-watch approach.
\end{abstract}

Keywords: Rectal cancer; Neoadjuvant chemoradiotherapy; Pathological complete response; Carcinoembryonic antigen

\section{Introduction}

Neoadjuvant chemoradiotherapy (nCRT) is currently offered to patients with locally advanced rectal cancer, and the combination of this strategy with total mesorectal excision (TME) is recommended as a standard procedure [1-3]. In a proportion of patients, nCRT results in a pathologic complete response ( $\mathrm{pCR}$ ), with no residual tumor identified in the surgical specimen. pCR carries a particular interest, for it seems to be associated not only with a better rate of local recurrence, but also with improved five-year overall and disease-free survival (DFS) [4-6].

Unfortunately, great differences in treatment response still exist among treated patients. Tumor downstaging can be obtained only in half of cases, and a pCR is reported to range between $19 \%$ and $36 \%$ [7-11]. Thus, there is a need to investigate validated biomarkers to distinguish between patients who have a high or low rate of well response, and to predict which patients are more likely to benefit from nCRT. In addition, it is of great importance to predict pathologically responding not completely to nCRT for patients achieving clinical complete response (cCR), since these patients are more unlikely to achieve PCR and should not be considered for a watchful waiting approach.
Recently, there is substantial evidence that clinical factors and biomolecular markers may be useful for identifying those patients who would achieve pCR after nCRT [9]. Carcinoembryonic antigen (CEA) is a tumor marker frequently used in a variety of clinical situations, including predicting metastasis, recurrence and prognosis [12], as well as monitoring response to chemotherapy treatment in colorectal cancer (CRC). Several studies have demonstrated conflicting results for the use of CEA as a significant predictor of response to nCRT. Some studies found that patients with a normal pretreatment CEA level $(<5$ $\mathrm{ng} / \mathrm{ml}$ ) had better responses to CRT than those with elevated CEA level $(\geq 5 \mathrm{ng} / \mathrm{ml})$ [13-20], while controversy exists in other studies [21,22]. We therefore performed a meta-analysis to evaluate the predictive value of pretreatment CEA levels, normally available in clinical practice, on the attainment of PCR after nCRT for rectal cancer.

\section{Materials and Methods}

\section{Literature search}

A literature search of MEDLINE, EMBASE, and the Cochrane library was performed on all the relevant studies (up to 30 January 2015) using the following keywords: "((Carcinoembryonic antigen) OR (CEA)) AND (rectal cancer) AND ((response) OR (regression)) [Title/ Abstract]". Articles were also identified using the "related articles" function. Moreover, we performed a manual search of references lists 
Citation: Huichuan Yu, Wenhao Chen, Yonghua Cai, Yanxin Luo, Liang Kang, et al. (2015) Pretreatment Serum Cea as a Predictive Biomarker for the Response to Neoadjuvant Chemoradiotherapy: A Meta-Analysis in Rectal Cancer. J Carcinog Mutagene 6: 237. doi: $10.4172 / 2157-2518.1000237$

Page 2 of 6

of retrieved articles and published reviews to search for additional related studies. Only studies published in English were included.

\section{Inclusion and exclusion criteria}

Studies selected from the initial search were subsequently included in this meta-analysis with the following criteria: (a) the study of interest was evaluation of CEA level for predicting the response to nCRT in locally-advanced rectal cancer, (b) assessment of pathological response was clearly defined, (c) CEA was evaluated as an categorized variable by the cut-off value equal to $5 \mathrm{ng} / \mathrm{ml}$, (d) retrospective or prospective design, and (e) the relative risk (RR) with $95 \% \mathrm{CI}$ (or data to calculate these) were reported. Reviews, letters to the editor, and case reports were excluded. Multiple studies of the same patient population were identified, the data sets of which were overlapped and duplicated.

\section{Data Extraction and Definitions}

Data were extracted independently from all eligible publications by two authors ( $\mathrm{Yu}$ and $\mathrm{Chen}$ ) and cross-checked to reach a consensus. If they failed to reach a consensus, a third investigator (Cai) was consulted to resolve the dispute. According to the inclusion criteria listed above, the following data were extracted for each study: the first author's name, publication year, study period, country of origin, study design, matching criteria. Sample size, treatment, pretreatment CEA level. Data of the main outcomes were listed in tables showing the pathological responses to CRT with respect to CEA level.

We used the definitions and standardizations for "normal" and "elevated" CEA level, as well as "response to CRT". One of the conflicts that arised concerning serum CEA level is the cut-off point for prediction. Different cutoff level for CEA was found to be significant for prediction of $\mathrm{pCR}$ in several studies. Most studies proposed 5 $\mathrm{ng} / \mathrm{ml}$ [13-27] and others $2.5 \mathrm{ng} / \mathrm{ml}[9,28], 3 \mathrm{ng} / \mathrm{ml}[29,30], 3.5 \mathrm{ng} / \mathrm{ml}$ $[31,32]$ or $6 \mathrm{ng} / \mathrm{ml}[22]$. Therefore, elevated CEA level was defined as $\geq$ $5 \mathrm{ng} / \mathrm{ml}$, and normal CEA level refers to $<5 \mathrm{ng} / \mathrm{ml}$ in current study. Pathologic response following nCRT was assessed by different tumor regression grade (TRG) systems. Most of the studies used TRG system described by Dworak et al. [33], which categorize tumour regression in five grades. Other studies simply assess the predictive effect of CEA on pCR without detailed report about TRG. According to most studies, we defined poor response (TRG 0-2), good response (TRG 3-4), and complete response (no residual tumor rate, TRG 4).

\section{Statistical Analysis}

Relative ratio (RR) estimates with 95\% CIs were combined using a random-effect (RE) model or a fixed-effects model, according to the heterogeneity $[34,35]$. Statistical heterogeneity among studies was assessed with Cochrane's $\mathrm{Q}$ test (considered significant for $\mathrm{P}<0.10$ ) and I2 statistics [36]. Sensitivity analysis was performed to evaluate the stability of the results, in which low-quality studies and each study was deleted each time.

An estimation of potential publication bias was executed by the funnel plot, in which an asymmetrical plot suggests a possible publication bias. All statistical tests were conducted by Review Manager Version 5.0 (The Cochrane Collaboration, Oxford, London, UK). The statistical tests were two-sided, and $\mathrm{P}<0.05$ was considered statistically significant.

The methodological quality of RCTs was assessed using the Cochrane Risk of Bias Tool [37]. The methodological quality of observational studies was assessed using the nine-star NewcastleOttawa Scale [38]. The quality of studies was assessed in accordance with six criteria in three domains: cohort selection, cohort comparability, and outcome. Stars were awarded for each criterion, and a score of 0 to 9 (allocated as stars) was allocated to each study. Studies achieving a score more than seven were considered to be of high quality.

\section{Results}

\section{Description of eligible studies}

As indicated in the search flow diagram (Figure 1), 14 studies [13-16,18-23,25-27] published from 2006 to 2015 fulfilled the inclusion criteria and were finally included in the meta-analysis. The characteristics of included studies are summarized in Table 1. A total of 3,705 patients from eligible studies were included. All the studies were retrospectively observational and performed in single center, except for a prospective study. The total number of patients per study ranged from 47 to 609 . Examination of the reference lists of these studies did not detect any further studies for evaluation.

\begin{tabular}{|c|c|c|c|c|c|c|c|c|c|c|c|}
\hline \multirow[b]{2}{*}{ Author } & \multirow[b]{2}{*}{ Year } & \multirow[b]{2}{*}{ Country } & \multirow[b]{2}{*}{$\begin{array}{l}\text { Study } \\
\text { Design }\end{array}$} & \multirow[b]{2}{*}{$\mathbf{N}$} & \multirow[b]{2}{*}{$\begin{array}{l}\text { Clinical } \\
\text { Stage }\end{array}$} & \multirow[b]{2}{*}{$\begin{array}{l}\text { Neoadjuvant } \\
\text { treatment }\end{array}$} & \multirow[b]{2}{*}{$\begin{array}{l}\text { Study } \\
\text { Quality }\end{array}$} & \multirow[b]{2}{*}{$\begin{array}{l}\text { Response } \\
\text { criteria }\end{array}$} & \multicolumn{3}{|c|}{$\begin{array}{l}\text { Provided information on pathologic } \\
\text { response }\end{array}$} \\
\hline & & & & & & & & & $\begin{array}{l}\text { poor } \\
\text { response }\end{array}$ & $\begin{array}{l}\text { good } \\
\text { response }\end{array}$ & $\begin{array}{l}\text { complete } \\
\text { response }\end{array}$ \\
\hline Kim HJ [27] & 2015 & Korea & retro & 102 & cll-IV & CRT & 8 & урTNM & урTNM II-IV & $\begin{array}{l}\text { ypTNM I and } \\
\text { pCR }\end{array}$ & NR \\
\hline Meng [26] & 2014 & Japan & retro & 314 & $\begin{array}{l}\text { cT2-4NO- } \\
2\end{array}$ & CRT & 9 & $\mathrm{pCR}$ & NR & NR & $\mathrm{pCR}$ \\
\hline Yeo [25] & 2013 & Korea & retro & 609 & $\begin{array}{l}\text { cT3-4NO- } \\
2 \mathrm{M} 0, \quad \text { cll- } \\
\text { III }\end{array}$ & CRT & 7 & $\begin{array}{l}\text { mTRG } \\
\text { Dworak }\end{array}$ & TRG 1-2 & TRG 3-4 & NR \\
\hline Wang [20] & 2013 & China & retro & 240 & cll-III & RT & 7 & $\begin{array}{l}\text { mTRG } \\
\text { Bateman [49] }\end{array}$ & $>5 \%$ residual & $<5 \%$ residual & $\mathrm{pCR}$ \\
\hline
\end{tabular}


Citation: Huichuan Yu, Wenhao Chen, Yonghua Cai, Yanxin Luo, Liang Kang, et al. (2015) Pretreatment Serum Cea as a Predictive Biomarker for the Response to Neoadjuvant Chemoradiotherapy: A Meta-Analysis in Rectal Cancer. J Carcinog Mutagene 6: 237. doi: $10.4172 / 2157-2518.1000237$

Page 3 of 6

\begin{tabular}{|c|c|c|c|c|c|c|c|c|c|c|c|}
\hline Lee [17] & 2013 & Korea & retro & 345 & $\begin{array}{l}\text { cT2-4NO- } \\
2 \mathrm{MO}\end{array}$ & CRT & 9 & $\mathrm{pCR}$ & NR & NR & $\mathrm{pCR}$ \\
\hline Restivo [18] & 2013 & Italy & retro & 260 & cll-III & CRT & 9 & $\mathrm{pCR}$ & NR & NR & $\mathrm{pCR}$ \\
\hline Huh [16] & 2013 & Korea & retro & 391 & ClI-III & CRT & 9 & $\mathrm{pCR}$ & NR & NR & $\mathrm{pCR}$ \\
\hline Wallin [19] & 2013 & USA & retro & 469 & $\begin{array}{l}\text { cT1-4N0- } \\
2\end{array}$ & CRT & 8 & $\mathrm{pCR}$ & NR & NR & $\mathrm{pCR}$ \\
\hline Yan [24] & 2011 & China & retro & 98 & $\begin{array}{l}\text { cT3-4N-/N } \\
+\end{array}$ & CRT & 6 & $\begin{array}{l}\text { mTRG } \\
\text { Dworak }\end{array}$ & TRG 0-2 & TRG 3-4 & NR \\
\hline $\begin{array}{l}\text { Moureau } \\
\text { [15] }\end{array}$ & 2011 & France & retro & 168 & $\begin{array}{l}\text { cT2-4N-/N } \\
+\end{array}$ & CRT & 8 & $\mathrm{pCR}$ & NR & NR & $\mathrm{pCR}$ \\
\hline Lin [21] & 2010 & China & $\begin{array}{l}\text { prospec- } \\
\text { tive }\end{array}$ & 47 & $\begin{array}{l}\text { cT3-4N-/N } \\
+\end{array}$ & CRT & 6 & $\begin{array}{l}\text { mTRG } \\
\text { Dworak }\end{array}$ & TRG 0-2 & TRG 3 & TRG 4 \\
\hline Perez [14] & 2009 & Brazil & retro & 170 & cl-III & CRT & 7 & $\mathrm{pCR}$ & $N R$ & NR & $\mathrm{pCR}$ \\
\hline $\begin{array}{l}\text { Yoon SM } \\
{[13]}\end{array}$ & 2007 & Korea & retro & 351 & $\begin{array}{l}\text { cT3-4N-/N } \\
+\end{array}$ & CRT & 7 & $\begin{array}{l}\text { mTRG } \\
\text { Dworak }\end{array}$ & TRG 1-2 & TRG 3-4 & TRG 4 \\
\hline Park [23] & 2006 & Korea & retro & 141 & $\begin{array}{l}\text { cT2-4N-/N } \\
+\end{array}$ & CRT & 7 & Park[23] & $\begin{array}{l}\text { Remained } \\
\text { patients }\end{array}$ & $\begin{array}{l}\text { only focal } \\
\text { residual }\end{array}$ & $\mathrm{pCR}$ \\
\hline
\end{tabular}

Table1: Characteristics of included studies.

Patients received nCRT in 13 studies and neoadjuvant RT was given in one study (Table 1). All the studies selected $5 \mathrm{ng} / \mathrm{ml}$ as the cut-off point for CEA level to predict pathological response. Ten of the studies were conducted in East Asian populations (2,638,71\%), while four of the studies were conducted in European or American populations with mixed but mostly white participants $(1,067,29 \%)$.

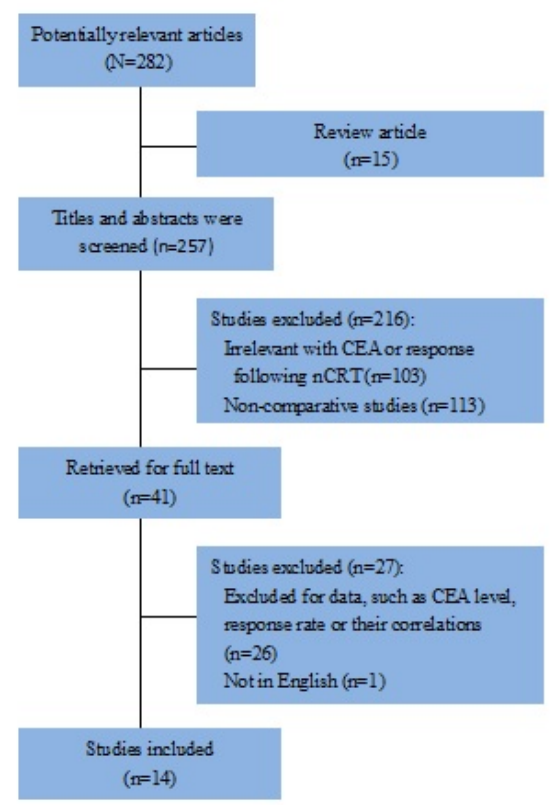

Figure 1: Flow diagram of studies identified, included and excluded

\section{Elevated versus normal CEA level}

Pooled data from the ten studies involving 2,359 patients contributed data on complete response setting showed pretreatment normal CEA level was significantly associated with improved complete response to nCRT (FE: RR 3.45; 95\% CI 2.66-4.46; P <0.00001)(Figure 2 ). The result of the nCRT, calculated separately with exclusion of one study using neoadjuvant RT, showed the same significant correlation (FE: RR 3.33; 95\% CI 2.57-4.31; $\mathrm{P}<0.00001$ ). Similarly in the analysis of five studies involving 1,296 patients, pretreatment normal CEA level was significantly correlated with good response (FE: RR 1.86; 95\% CI $1.08-3.21 ; \mathrm{P}<0.00001$ ) (Figure 3). According to the analysis of the four studies involving 1,198 patients that consistently assessed poor response, normal CEA level was significantly associated with decreases in poor response (RE: RR 0.77; 95\% CI $0.72-0.82$; $\mathrm{P}<0.00001$ ) (Figure 4).

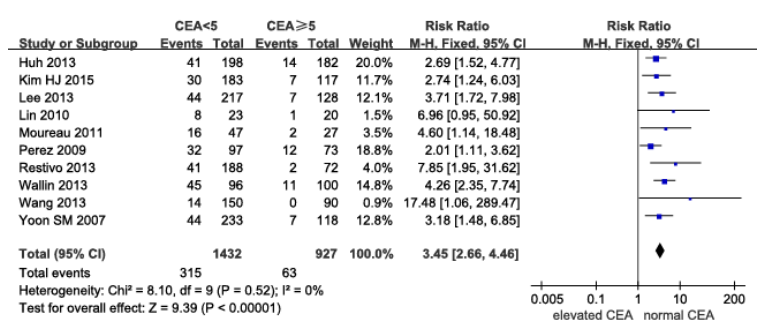

Figure 2: Forest plots of RR were assessed for association between pretreatment CEA and pathologic complete response to neoadjuvant CRT 
Citation: Huichuan Yu, Wenhao Chen, Yonghua Cai, Yanxin Luo, Liang Kang, et al. (2015) Pretreatment Serum Cea as a Predictive Biomarker for the Response to Neoadjuvant Chemoradiotherapy: A Meta-Analysis in Rectal Cancer. J Carcinog Mutagene 6: 237. doi: $10.4172 / 2157-2518.1000237$

Page 4 of 6

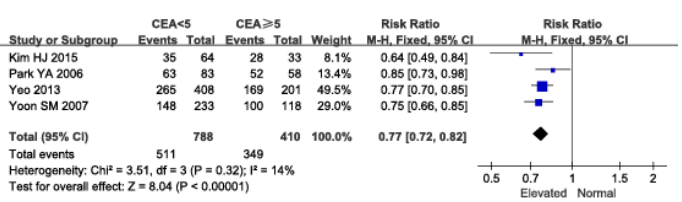

Figure 3: Forest plots of RR were assessed for association between pretreatment CEA and good response to neoadjuvant CRT

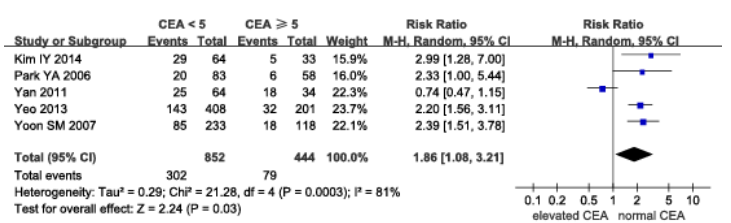

Figure 4: Forest plots of RR were assessed for association between pretreatment CEA and poor response to neoadjuvant CRT

\section{Sensitivity analysis and publication bias}

Sensitivity analysis was carried out to assess the influence of individual studies and low-quality studies on the summary effect. The results suggest that the influence of each individual data set to the pooled RRs is not significant. The funnel plot for CEA level and pCR rate is shown in Figure 5. The top of the funnel plots showed no evidence of obvious asymmetry, while the bottom showed asymmetry, indicating the potential publication bias.

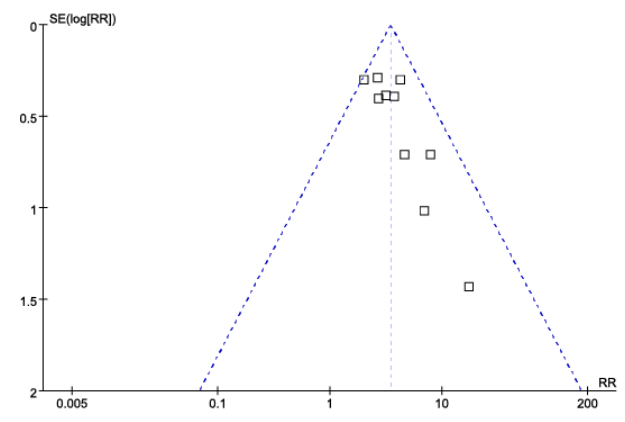

Figure 5: Funnel plot of pretreatment CEA level and pCR rate

\section{Discussion}

The present meta-analysis of 14 studies systematically evaluated the association between CEA level and response to nCRT in a large population. The results indicate that pretreatment normal CEA level $(<5 \mathrm{ng} / \mathrm{ml})$ predicts improved pCR and good response and decreased poor response to neoadjuvant therapy in patients with rectal cancer. Further stratification according to different neoadjuvant therapies showed that this association remained. We interpret normal CEA level as a valid biomarker predicting patients are likely to benefit from nCRT.
Only studies using $5 \mathrm{ng} / \mathrm{ml}$ as the cut-off point for CEA level to predict pathological response were included in our study, while 2.5 $\mathrm{ng} / \mathrm{ml}[9,28], 3 \mathrm{ng} / \mathrm{ml}$ [29] or $3.5 \mathrm{ng} / \mathrm{ml}$ [31] was also found to be significant for prediction of $\mathrm{pCR}$, good response or poor response in selected excluded studies, determined by performed receiver operating characteristic (ROC) curves. Briefly, all the selected studies showed that normal CEA level (<cut-off point: 5, 3.5, 3 or $2.5 \mathrm{ng} / \mathrm{ml}$ ) is correlated with improved pathologic response to neoadjuvant therapy, while high CEA level ( $\geq$ cut-off point: $5,3.5,3$ or $2.5 \mathrm{ng} / \mathrm{ml}$ ) may predict increased poor response.

TRG system as mentioned above is the most popular way to assess the response of primary tumors after the introduction of neoadjuvant CRT, which correlates with DFS as an independent factor based on several retrospective studies $[1,4,5,39,40]$. It is of significant importance to predict patients who will perform well in TRG assessment system before the neoadjuvant CRT, because it will be a waste of time for patient who would not response well to neoadjuvant CRT and may miss the best opportunity to receive surgical treatment. For this reason, other biomarkers and genetic predictors, such as $\mathrm{p} 21$, p53, Bax, Bcl2, COX2, VEGF, EGFR and thymidylate synthase [41-43], have been studied. Some newly predictive biomarkers are also reported, including Cathepsin S [44], expression of CD133 [45], methylation of long interspersed nuclear element-1(LINE-1) [46], and GRP78 the 78-kDa glucose-regulated protein [47], but some of them are contradictory. These new biomarkers may help predict which patients may respond, but they could not directly translate into widely and low-cost clinical use. It is important to develop serum CEA, a clinical variable that can potentially be used in the clinical setting.

Since cCR does not necessarily imply pCR, whether watch-and-wait strategy can be pursued instead of routine surgery in patients who achieve CCR after nCRT is still debated [48]. Based on our results, patients with elevated pretreatment CEA are more unlikely to have a pCR. Therefore, the enrolled patients achieving cCR with elevated pretreatment CEA should not be considered for a wait-and-watch approach in further clinical studies designed to determine its safety and efficacy.

The present meta-analysis has the following limitations that need to be acknowledged. First, most of the studies included were retrospective, and the small number of cases in two studies also decreased the reliability of the results, which made it difficult to acquire strong evidence for the conclusions. Second, available data are still sparse, and in-depth analyses of the associations in the context of different cut-off values, TRG assessments, CRT regimens and intervals between CRT and surgery are highly desirable to enable more-precise estimates and a better understanding of the role of CEA in predicting response to neoadjuvant CRT. Third, there was significant variability in terms of cut-off values of CEA level among studies we first retrieved. We exclude the studies not using $5 \mathrm{ng} / \mathrm{ml}$ as the cut-off value to reach the comparability between studies, which may have contributed to the selection bias. Use of the RE model for pooled data might minimize the effects of heterogeneity, but does not abolish them. Finally, some authors did not report the proportion of patients lost to follow-up, which may influence the reliability of the conclusions.

Despite these limitations, some advantages of the current metaanalysis should be addressed. First, the number of total cases and controls were substantial, and the studies included were conducted at major institutions in different continents. Therefore, the patients evaluated may reflect patient populations around the world which significantly increased the statistical power of the analysis. Second, we 
Citation: Huichuan Yu, Wenhao Chen, Yonghua Cai, Yanxin Luo, Liang Kang, et al. (2015) Pretreatment Serum Cea as a Predictive Biomarker for the Response to Neoadjuvant Chemoradiotherapy: A Meta-Analysis in Rectal Cancer. J Carcinog Mutagene 6: 237. doi: $10.4172 / 2157-2518.1000237$

Page 5 of 6

applied multiple strategies to identify studies, and strict criteria to include and evaluate the quality of the studies. Sensitivity analysis confirmed the reliability of the pooled estimates in the meta-analysis, and no publication biases were detected, which indicates that the entire pooled result may be unbiased. Third, we clearly defined grade of CEA level and assessment of response. Cut-off values of pretreatment CEA were the same in each study, which might avoid inconsistent results between these studies and help to obtain accurate data with clinical significance.

This is the first meta-analysis to assess the value of pretreatment CEA level for predicting the response of rectal cancer patients to neoadjuvant therapy. This study was conducted at an appropriate time because enough data have accumulated for inspection by metaanalytical methods at a time when the value of serum CEA levels in predicting response to nCRT has been assessed frequently, particularly, in recent two years. This analysis therefore provides the most up-todate information in this area.

\section{Conclusions}

The current meta-analysis suggests that pretreatment normal CEA level is a useful predictive factor for response to neoadjuvant chemoradiotherapy in patients with rectal cancer. The validated predictive value of pretreatment CEA on pCR should be considered in the design of further clinical studies to determine the safety and efficacy of wait-and-watch approach.

\section{Acknowledgments}

Support for these studies was provided by a Program of Introducing Talents of Discipline to Universities of China (B12003, JW) and International Science \& Technology Cooperation Program of China (2011DFA32570, JW), National Natural Science Foundation of China (81172040 JW;81201920, YL).

\section{Conflict of Interest}

The authors declare that they have no conflict of interest.

\section{Author Disclosure Statement}

The authors reported no proprietary or commercial interest in any product mentioned or concept discussed in the article.

\section{References}

1. Kapiteijn E, Marijnen CA, Nagtegaal ID, Putter H, Steup WH, et al. (2001) Preoperative radiotherapy combined with total mesorectal excision for resectable rectal cancer. N Engl J Med 345: 638-646.

2. Sauer R, Becker H, Hohenberger W, Rödel C, Wittekind C, et al. (2004) Preoperative versus postoperative chemoradiotherapy for rectal cancer. $\mathrm{N}$ Engl J Med 351: 1731-1740.

3. Wong RK, Tandan V, De Silva S, Figueredo A (2007) Pre-operative radiotherapy and curative surgery for the management of localized rectal carcinoma. Cochrane Database Syst Rev : CD002102.

4. Quah HM, Chou JF, Gonen M, Shia J, Schrag D, et al. (2008) Pathologic stage is most prognostic of disease-free survival in locally advanced rectal cancer patients after preoperative chemoradiation. Cancer 113: 57-64.

5. Roh MS, Colangelo LH, O'Connell MJ, Yothers G, Deutsch M, et al. (2009) Preoperative multimodality therapy improves disease-free survival in patients with carcinoma of the rectum: NSABP R-03. J Clin Oncol 27: 5124-5130.
6. Park YJ, Oh BR, Lim SW, Huh JW, Joo JK, et al. (2010) Clinical significance of tumor regression grade in rectal cancer with preoperative chemoradiotherapy. J Korean Soc Coloproctol 26: 279-286.

7. Janjan NA, Khoo VS, Abbruzzese J, Pazdur R, Dubrow R, et al. (1999) Tumor downstaging and sphincter preservation with preoperative chemoradiation in locally advanced rectal cancer: the M. D. Anderson Cancer Center experience. Int J Radiat Oncol Biol Phys 44: 1027-1038.

8. Pucciarelli S, Toppan P, Friso ML, Russo V, Pasetto L, et al. (2004) Complete pathologic response following preoperative chemoradiation therapy for middle to lower rectal cancer is not a prognostic factor for a better outcome. Dis Colon Rectum 47: 1798-1807.

9. Das P, Skibber JM, Rodriguez-Bigas MA, Feig BW, Chang GJ, et al. (2007) Predictors of tumor response and downstaging in patients who receive preoperative chemoradiation for rectal cancer. Cancer 109: 1750-1755.

10. Carlomagno C, Farella A, Bucci L, D'Armiento FP, Pesce G, et al. (2009) Neo-adjuvant treatment of rectal cancer with capecitabine and oxaliplatin in combination with radiotherapy: a phase II study. Ann Oncol 20: 906-912.

11. Kalady MF, de Campos-Lobato LF, Stocchi L, Geisler DP, Dietz D, et al. (2009) Predictive factors of pathologic complete response after neoadjuvant chemoradiation for rectal cancer. Ann Surg 250: 582-589.

12. Mitchell EP (1998) Role of carcinoembryonic antigen in the management of advanced colorectal cancer. Semin Oncol 25: 12-20.

13. Yoon SM, Kim DY, Kim TH, Jung KH, Chang HJ, et al. (2007) Clinical parameters predicting pathologic tumor response after preoperative chemoradiotherapy for rectal cancer. Int J Radiat Oncol Biol Phys 69: 1167-1172.

14. Perez RO, São Julião GP, Habr-Gama A, Kiss D, Proscurshim I, et al. (2009) The role of carcinoembriogenic antigen in predicting response and survival to neoadjuvant chemoradiotherapy for distal rectal cancer. Dis Colon Rectum 52: 1137-1143.

15. Moureau-Zabotto L, Farnault B, de Chaisemartin C, Esterni B, Lelong B, et al. (2011) Predictive factors of tumor response after neoadjuvant chemoradiation for locally advanced rectal cancer. Int J Radiat Oncol Biol Phys 80: 483-491.

16. Huh JW, Kim HR, Kim YJ (2013) Clinical prediction of pathological complete response after preoperative chemoradiotherapy for rectal cancer. Dis Colon Rectum 56: 698-703.

17. Lee JH, Kim SH, Jang HS, Chung HJ, Oh ST, et al. (2013) Preoperative elevation of carcinoembryonic antigen predicts poor tumor response and frequent distant recurrence for patients with rectal cancer who receive preoperative chemoradiotherapy and total mesorectal excision: a multiinstitutional analysis in an Asian population. Int J Colorectal Dis 28: 511-517.

18. Restivo A, Zorcolo L, Cocco IM, Manunza R, Margiani C, et al. (2013) Elevated CEA levels and low distance of the tumor from the anal verge are predictors of incomplete response to chemoradiation in patients with rectal cancer. Ann Surg Oncol 20: 864-871.

19. Wallin U, Rothenberger D, Lowry A, Luepker R, Mellgren A (2013) CEA a predictor for pathologic complete response after neoadjuvant therapy for rectal cancer. Dis Colon Rectum 56: 859-868.

20. Wang L, Zhong XG, Peng YF, Li ZW, Gu J (2013) Prognostic value of pretreatment carcinoembryonic antigen level on tumour downstaging and early occurring metastasis in locally advanced rectal cancer following 30gy/10f neoadjuvant radiotherapy. Colorectal Dis 16: 33-39.

21. Lin JZ, Zeng ZF, Wu XJ, Wan DS, Chen G, et al. (2010) Phase II study of pre-operative radiotherapy with capecitabine and oxaliplatin for rectal cancer and carcinoembryonic antigen as a predictor of pathological tumour response. J Int Med Res 38: 645-654.

22. Yang KL, Yang SH, Liang WY, Kuo YJ, Lin JK, et al. (2013) Carcinoembryonic antigen (CEA) level, CEA ratio, and treatment outcome of rectal cancer patients receiving pre-operative chemoradiation and surgery. Radiat Oncol 8: 43.

23. Park YA, Sohn SK, Seong J, Baik SH, Lee KY, et al. (2006) Serum CEA as a predictor for the response to preoperative chemoradiation in rectal cancer. J Surg Oncol 93: 145-150. 
Citation: Huichuan Yu, Wenhao Chen, Yonghua Cai, Yanxin Luo, Liang Kang, et al. (2015) Pretreatment Serum Cea as a Predictive Biomarker for the Response to Neoadjuvant Chemoradiotherapy: A Meta-Analysis in Rectal Cancer. J Carcinog Mutagene 6: 237. doi: $10.4172 / 2157-2518.1000237$

Page 6 of 6

24. Yan H, Wang R, Zhu K, Zhao W, Jiang S, et al. (2011) Predictors of sensitivity to preoperative chemoradiotherapy of rectal adenocarcinoma. Tumori 97: 717-723.

25. Yeo SG, Kim DY, Chang HJ, Park JW, Oh JH, et al. (2013) Reappraisal of pretreatment carcinoembryonic antigen in patients with rectal cancer receiving preoperative chemoradiotherapy. Tumori 99: 93-99.

26. Meng X, Huang Z, Wang R, Jiao Y, Li H, et al. (2014) The prognostic role of EZH2 expression in rectal cancer patients treated with neoadjuvant chemoradiotherapy. Radiat Oncol 9: 188.

27. Kim HJ, Choi GS, Park JS, Park S, Kawai K, et al. (2015) Clinical significance of thrombocytosis before preoperative chemoradiotherapy in rectal cancer: predicting pathologic tumor response and oncologic outcome. Ann Surg Oncol 22: 513-519.

28. Moreno GV, Cejas P, Blanco CM, Feliu BJ, de Castro Carpeno J, et al. (2009) Prognostic value of carcinoembryonic antigen level in rectal cancer treated with neoadjuvant chemoradiotherapy. Int J Colorectal Dis 24: 741-748.

29. Park JW, Lim SB, Kim DY, Jung KH, Hong YS, et al. (2009) Carcinoembryonic antigen as a predictor of pathologic response and a prognostic factor in locally advanced rectal cancer patients treated with preoperative chemoradiotherapy and surgery. Int J Radiat Oncol Biol Phys 74: 810-817.

30. Yoon HI, Koom WS, Kim YB, Min BS, Lee KY, et al. (2014) Predicting the pathologic response of locally advanced rectal cancer to neoadjuvant concurrent chemoradiation using enzyme-linked immunosorbent assays (ELISAs) for biomarkers. J Cancer Res Clin Oncol 140: 399-409.

31. Jang NY, Kang SB, Kim DW, Kim JH, Lee KW, et al. (2011) The role of carcinoembryonic antigen after neoadjuvant chemoradiotherapy in patients with rectal cancer. Dis Colon Rectum 54: 245-252.

32. Kim IY, You SH, Kim YW (2014) Neutrophil-lymphocyte ratio predicts pathologic tumor response and survival after preoperative chemoradiation for rectal cancer. BMC Surg 14: 94.

33. Dworak O, Keilholz L, Hoffmann A (1997) Pathological features of rectal cancer after preoperative radiochemotherapy. Int J Colorectal Dis 12: 19-23.

34. DerSimonian R, Laird N (1986) Meta-analysis in clinical trials. Control Clin Trials 7: 177-188.

35. Clarke M, Horton R (2001) Bringing it all together: Lancet-Cochrane collaborate on systematic reviews. Lancet 357: 1728.

36. Higgins JP, Thompson SG (2002) Quantifying heterogeneity in a metaanalysis. Stat Med 21: 1539-1558.

37. Higgins J GS (2008) Cochrane Handbook for Systematic Reviews of Interventions: Cochrane Book Series. Chichester: The Cochrane Collaboration and John Wiley \& Sons Ltd.
38. Stang A (2010) Critical evaluation of the Newcastle-Ottawa scale for the assessment of the quality of nonrandomized studies in meta-analyses. Eur J Epidemiol 25: 603-605.

39. Rodel C, Martus P, Papadoupolos T, Fuzesi L, Klimpfinger M, et al. (2005) Prognostic significance of tumor regression after preoperative chemoradiotherapy for rectal cancer. J Clin Oncol 23: 8688-8696.

40. Losi L, Luppi G, Gavioli M, Iachetta F, Bertolini F, et al. (2006) Prognostic value of Dworak grade of regression (GR) in patients with rectal carcinoma treated with preoperative radiochemotherapy. Int J Colorectal Dis 21: 645-651.

41. Ghadimi BM, Grade M, Difilippantonio MJ, Varma S, Simon R, et al. (2005) Effectiveness of gene expression profiling for response prediction of rectal adenocarcinomas to preoperative chemoradiotherapy. J Clin Oncol 23: 1826-1838.

42. Smith FM, Reynolds JV, Miller N, Stephens RB, Kennedy MJ (2006) Pathological and molecular predictors of the response of rectal cancer to neoadjuvant radiochemotherapy. Eur J Surg Oncol 32: 55-64.

43. Karlberg M, Ohrling K, Edler D, Hallström M, Ullén H, et al. (2010) Prognostic and predictive value of thymidylate synthase expression in primary colorectal cancer. Anticancer Res 30: 645-651.

44. Gormley JA, Hegarty SM, O'Grady A, Stevenson MR, Burden RE, et al. (2011) The role of Cathepsin S as a marker of prognosis and predictor of chemotherapy benefit in adjuvant CRC: a pilot study. Br J Cancer 105: 1487-1494.

45. Ong CW, Kim LG, Kong HH, Low LY, Iacopetta B, et al. (2010) CD133 expression predicts for non-response to chemotherapy in colorectal cancer. Mod Pathol 23: 450-457.

46. Kawakami K, Matsunoki A, Kaneko M, Saito K, Watanabe Get al. (2011) Long interspersed nuclear element-1 hypomethylation is a potential biomarker for the prediction of response to oral fluoropyrimidines in microsatellite stable and $\mathrm{CpG}$ island methylator phenotype-negative colorectal cancer. Cancer Sci 102: 166-174.

47. Thornton M, Aslam MA, Tweedle EM, Ang C, Campbell F, et al. (2013) The unfolded protein response regulator GRP78 is a novel predictive biomarker in colorectal cancer. Int J Cancer 133: 1408-1418.

48. Das P, Minsky BD2 (2013) A watch-and-wait approach to the management of rectal cancer. Oncology (Williston Park) 27: 962-968.

49. Bateman AC, Jaynes E, Bateman AR (2009) Rectal cancer staging post neoadjuvant therapy--how should the changes be assessed? Histopathology 54: 713-721. 